(C) 2006 IEEE. Reprinted, with permission, from Youguang Guo, Modeling and Simulation of Flyback DC-DC Converter under Heavy Load . Communications, Circuits and Systems Proceedings, 2006 International Conference on (Volume:4 ), 2006. This material is posted here with permission of the IEEE. Such permission of the IEEE does not in any way imply IEEE endorsement of any of the University of Technology, Sydney's products or services. Internal or personal use of this material is permitted. However, permission to reprint/republish this material for advertising or promotional purposes or for creating new collective works for resale or redistribution must be obtained from the IEEE by writing to pubs-permissions@ieee.org. By choosing to view this document, you agree to all provisions of the copyright laws protecting it 


\section{Modeling and Simulation of Flyback DC-DC Converter under Heavy Load}

\author{
Jiaxin Chen \\ College of Electromechanical \\ Engineering \\ Donghua University \\ Shanghai, China \\ chjiaxin@dhu.edu.cn
}

\author{
Jianguo Zhu, Youguang Guo \\ Faculty of Engineering \\ University of Technology, Sydney \\ Sydney, NSW, Australia \\ joe@eng.uts.edu.au, \\ youguang@eng.uts.edu.au
}

\author{
Jianxun Jin \\ School of Automation Engineering \\ University of Electronic Science and \\ Technology of China \\ Chengdu, Sichuang, China \\ jxjin@uestc.edu.cn
}

\begin{abstract}
Appropriate simulation models of converters under heavy loads are crucial for designing a high reliability converter system. This paper presents the modeling and simulation of flyback DC-DC converters operating in heavy loads such as over-current and under-voltage modes, based on the concept of energy self-holding. An existing converter, which was once damaged in the experiment due to a shortcircuited output, is analyzed by the presented simulation models and is found to be likely damaged under a heavy load. According to the simulated results, the circuit and parameters of the converter are modified. The redesigned converter can work safely in both steady state and heavy load modes.
\end{abstract}

\section{INTRODUCTION}

Because of its simpler structure than other types of switching mode converters, the flyback converter is commonly used as small power converters. On the operational principle, design methodology, modeling, and control of the flyback converter, a great amount of work has been done and can be readily found in the literature [1-3]. The existing methods, however, rarely take into account the over-current and under-voltage protection circuits in the performance analysis due to the lack of appropriate simulation models. Therefore, there is always a discrepancy between the theoretical results and the performance of physical systems. As most of these methods are based on the steady state analysis, they cannot be employed to predict the transient behavior at starting or long period oscillation caused by a heavy load or short-circuited output terminals. In contrast to the steady state operation under a light or the rated load, the reliability is more seriously challenged when the converter is under a heavy load or with its output terminals short-circuited. In order to design a highly reliable product, it is essential to develop an effective method to model and simulate the flyback converter under heavy load.

Based on the previous work of the authors on the steady state performance analysis using the concepts of energy selfholding (ESH) and depth of ESH (DESH) in the flyback converter [4], this paper presents numerical simulation models of the converter under heavy load in various operational modes. The parameters in the models can be easily modified. The models can be used for transient analysis during starting, and also the operation in the undervoltage or in over-current mode, even in short-circuited output mode. By modifying the parameters according to the simulation results, the converter reliability can be significantly improved.

A practical small power flyback DC-DC converter, which was once damaged in the experiment because of a short-circuited output, is analyzed by the proposed models. It is found that the converter transformer is easy to saturate under a heavy load such that the converter is likely to be damaged. Based on the simulated results, the converter is redesigned by modifying the circuit and parameters. The new converter can operate safely in both the steady-state and heavy load modes.

\section{ANALYSIS OF FLYBACK DC-DC CONVERTER}

Fig. 1 shows a typical circuit of the flyback DC-DC converter with a single output port, where dashed lines connect control block to the main circuit.

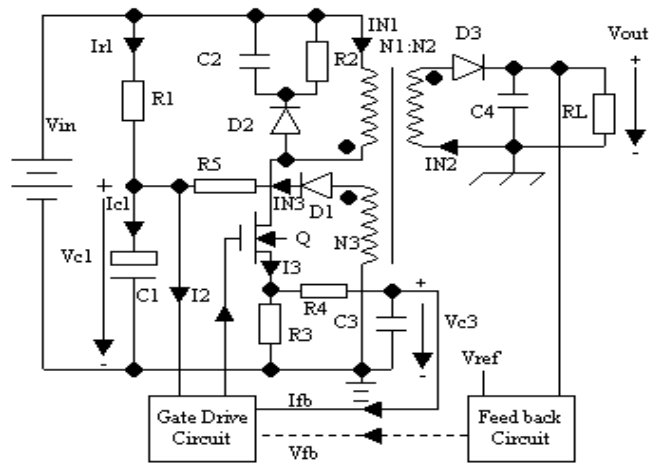

Figure 1. Typical circuit topology of flyback DC-DC converter 


\section{A. Output Voltage and Current Characteristics}

Fig. 1 includes three main blocks: the output voltage control block (VCB), the over-current protection (OCP) block, and the under-voltage protection (UVP) block. In the normal operation mode, the OCP and UVP circuits are not activated, and the converter operates as a constant voltage source, as shown by Section 1 in Fig. 2, where VN, IN, RN are the rated output voltage, current, and load resistance. When the load resistance is smaller than RN, and the output current exceeds the rated value, the OCP circuit is activated. In the OCP mode, Section 2 in Fig. 2, the VCB circuit of the converter is no longer functional and the output voltage drops rapidly. Limited by the OCP circuit, the output current increases very slowly, and the converter shows a non-ideal constant current source characteristic.

When the voltage drops below a critical value $V_{s}$, the UVP circuit is activated to prevent the damage caused by the short-circuited output terminals. In this mode, the terminal voltage of transformer coil N3 is too low to supply the PWM control chip, and the system operates in a starting-operationstopping-restarting oscillation status. The output current shows a large constant current long period oscillation characteristic, as shown by Section 3 in Fig. 2. In this section, the OCP limits the current in the primary coil of the transformer.

Table I lists the on/off states of each block corresponding to the operational modes, and Figs. 3(a) and (b) show the equivalent circuits for the OCP mode and UVP mode, respectively. Both the OCP and UVP modes belong to the heavy load mode. As there is a huge capacitor across the output port, the process of system start-up has the same characteristic as that of the system operating in the OCP mode. As the transformer is easy to saturate, many converters are damaged during the OCP or UVP mode, mostly in the latter mode.

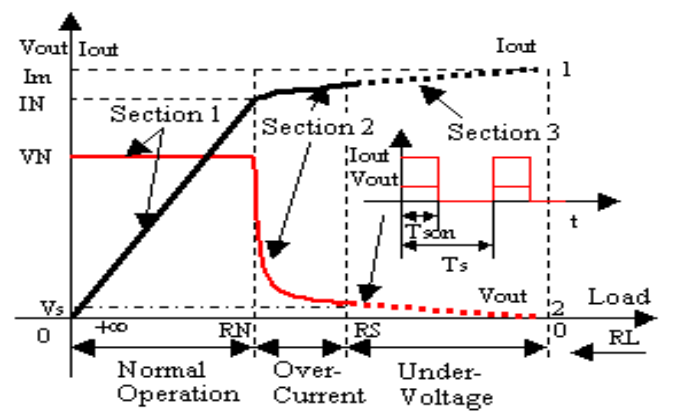

Figure 2. Output characteristics of flyback DC-DC converter

TABLE I. ON/OFF STATE OF THREE MAIN BLOCKS

\begin{tabular}{|l|c|c|c|}
\hline Operational mode & $\begin{array}{c}\text { VCB } \\
\text { Block }\end{array}$ & $\begin{array}{c}\text { OCP } \\
\text { Block }\end{array}$ & $\begin{array}{c}\text { UVP } \\
\text { Block }\end{array}$ \\
\hline VCB Mode & On & Off & Off \\
\hline OCP Mode & Off & On & Off \\
\hline UVP Mode & Off & On & On \\
\hline
\end{tabular}



(a)

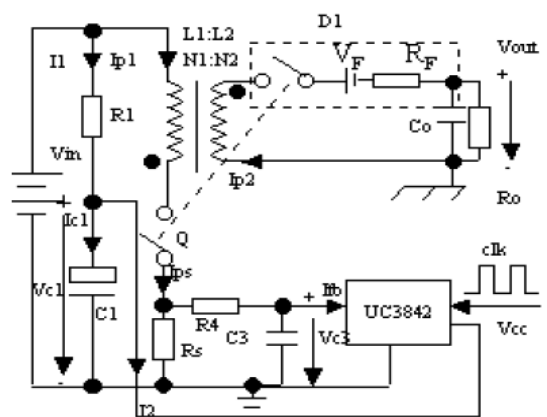

(b)

Figure 3. Equivalent circuit of the system with heavy load: (a) in OCP mode, (b) in UVP mode

\section{B. Energy Characteristics}

In the analysis of energy characteristics, concepts of ESH and DESH are employed. The ESH (energy self-holding) is defined as the amount of input energy held by a lossless energy transform device, e.g. a transformer when the copper and core losses are ignored in this case, and the DESH (depth of energy self-holding) is accordingly defined as the ratio between the energy held by the lossless transform device and the total input energy [4].

In the normal operational mode, the transformer operates in a discontinuous state and most of the input energy to the transformer is delivered to the load, so DESH $\approx 0$. When the converter operates in the OCP, the transformer starts to work in the continuous conduction state, and the energy held by the transformer starts to increase, i.e. DESH $>0$. When the UVP is activated, the transformer operates in continuous mode with a very high DESH, and when the output terminals are short-circuited, DESH $=100 \%$.

Fig. 4 plots the DESH, and the normalized transformer input energy $E_{T i n}$, maximum and minimum energy that the transformer may hold, $E_{T \max }$ and $E_{T \min }$, and the output energy to the load, $E_{\text {Tout }}$, corresponding to the three operational modes. As shown, when the converter operates in Section 3, a great percentage of the input energy will be stored in the transformer and the transformer core will get deeply saturated. A direct consequence of this is to cause irreversible damage to physical devices, such as the transformer coils and/or the power switching devices. 




Figure 4. Energy characteristics

\section{Atomic Circuit Blocks}

In order to build the simulation model, it is necessary to find out the relations between different components in the system in advance. However, as there are so many components in the converter, it is very difficult for the simulation model to be set up in a simple step. The system may be disassembled to several atomic circuit blocks (ACBs), defined as the possible minimum unit with a complete function, and then the relations among these blocks are built for simulation of the complete system. The components in the same ACB work or stop simultaneously, and perform a task together. According to this principle and the above assumptions, several ACBs of the system operating in heavy load can be obtained, as shown in Table II. The main components of ACBs are also listed in the table.

\section{Analysis of IC-UC3842 in Heavy Load}

The functional block diagram of UC3842 is illustrated in Fig. 5. The voltage of VCC for starting is $\mathrm{V}_{\text {START }}=16 \mathrm{~V}$. When $V_{c 1} \geq 16 \mathrm{~V}$, UC3842 is in starting mode, and after starting, if $V_{c 1} \leq 10 \mathrm{~V}$, the UVP embedded in UC3842 will stop the PWM output, as illustrated in Fig. 6(a).

There are two methods which can cause the system into the OCP mode by using either the COMP (1), or the ISENSE (6). Under heavy load, because the output voltage is lower than the rated value and the voltage of COMP (1) is above $4.4 \mathrm{~V}$, only the $1 \mathrm{~V}$ voltage of ISENSE (6) can cause the system into the OCP mode. The delayed time, $\mathrm{T}_{\mathrm{DELAY}}$, to output is about $150 \mathrm{~ns}$. The equivalent circuit of the time delay and the OCP function is shown in Fig. 6(b).

Based on the energy conservation, UC3842 in the ON state is modeled by a resistance of $\mathrm{R}_{\mathrm{ICON}}=1360 \Omega$, and in the OFF state by a very large resistance, $\mathrm{R}_{\mathrm{ICOFF}}$ e.g. $2 \mathrm{M} \Omega$. The equivalent circuit of power consumption is shown in Fig. 6(c).

The typical rise time and fall time of the output section of UC3842, according to the manual, are both 50 ns, maximum 150 ns. In order to maximize the system safety when operating in the heavy load mode, the rise time, $T_{\text {RISE }}$ is chosen as $50 \mathrm{~ns}$, and the fall time, $\mathrm{T}_{\mathrm{FALL}}$ is chosen as $150 \mathrm{~ns}$. Its transfer functional diagram of delay is shown in Fig. 6(d).
TABLE II. ACBS AND MAIN COMPONENTS

\begin{tabular}{|l|l|l|}
\hline No. & ACBs & Components \\
\hline 1 & VCC Charger & R1, C1, $\mathrm{R}_{\text {ICON }}, \mathrm{R}_{\text {ICOFF }}$ \\
\hline 2 & UVP & $\mathrm{U}_{\text {START }}, \mathrm{U}_{\text {STOP }}$ \\
\hline 3 & RC FILTER & R4, Rs, C3 \\
\hline 4 & OCP & $1 \mathrm{~V}$ Comparator, $\mathrm{T}_{\text {DELAY }}$ \\
\hline 5 & RC OUT & $\mathrm{C}_{0}, \mathrm{R}_{\mathrm{o}}$ \\
\hline 6 & Transformer & Lm1, Lm2, $\mathrm{R}_{\text {INF }}$ \\
\hline 7 & Equivalent Source & $\mathrm{D} 1: \mathrm{V}_{\mathrm{F}}, \mathrm{R}_{\mathrm{F}}$ \\
\hline 8 & Synchronizer & CLK \\
\hline
\end{tabular}

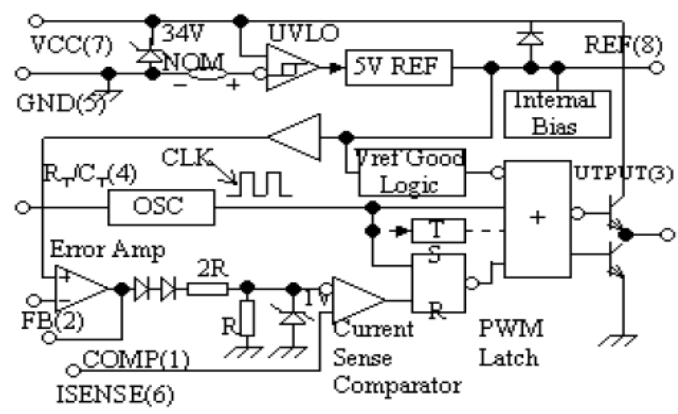

Figure 5. Functional block diagram of UC3842



(a) Hysteresis loop of start-up

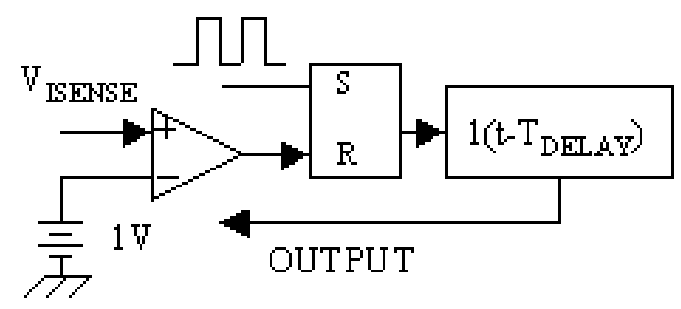

(b) Equivalent circuit of output time delay and OCP function

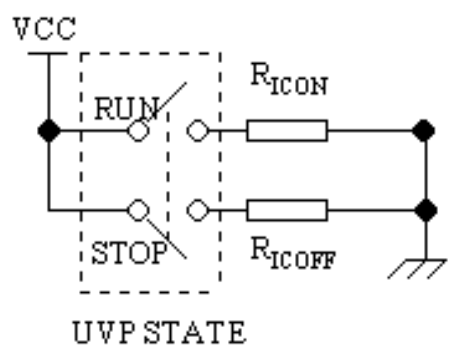

(c) The equivalent circuit of IC power consumption 
OUTPUT

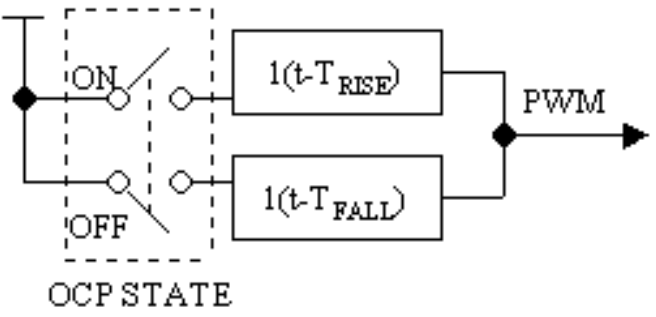

(d) Transfer functional diagram of delay in ON, OFF state

Figure 6. Several processes of IC-UC3842 in heavy load

\section{SiMULATION MODELS}

Table III lists several ACBs and their corresponding input, output and state signals. According to Fig. 3, Table II, Table III and the working principle of the flyback converter, the SIMULINK/MATALB based simulation model of each ACB can be obtained, as illustrated in Fig. 7. Based on the previous analysis and ACB models, a complete simulation model of the flyback converter can be achieved, as in Fig. 8.

TABLE III. ACBS AND CORRESPONDING OUTPUT SIGNAL, INPUT SignAL, AND STATE SignAL

\begin{tabular}{|l|l|l|l|}
\hline ACB & Input signal & Output signal & State signal \\
\hline VCC charger & $\mathrm{V}_{\mathrm{IN}}$ & VCC & UVP \\
\hline RC filter & $\mathrm{I}_{\mathrm{P} 1}$ & $\mathrm{~V}_{\mathrm{C} 3}$ & PWM \\
\hline RC OUT & $\mathrm{I}_{\mathrm{P} 2}$ & $\mathrm{~V}_{\mathrm{OUT}}$ & PWM, CM \\
\hline Transformer & VCC, $\mathrm{V}_{\mathrm{D}}, \mathrm{V}_{\text {OUT }}$ & $\mathrm{I}_{\mathrm{P} 1}, \mathrm{I}_{\mathrm{P} 2}$ & PWM, CM \\
\hline
\end{tabular}



(a)

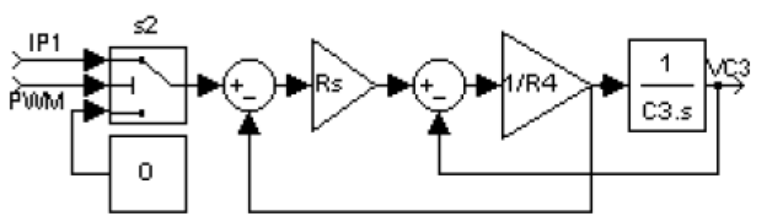

(b)

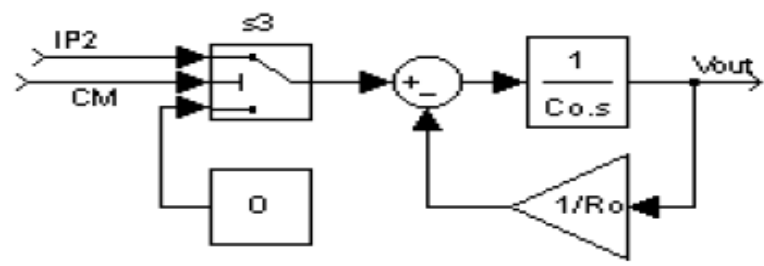

(c)

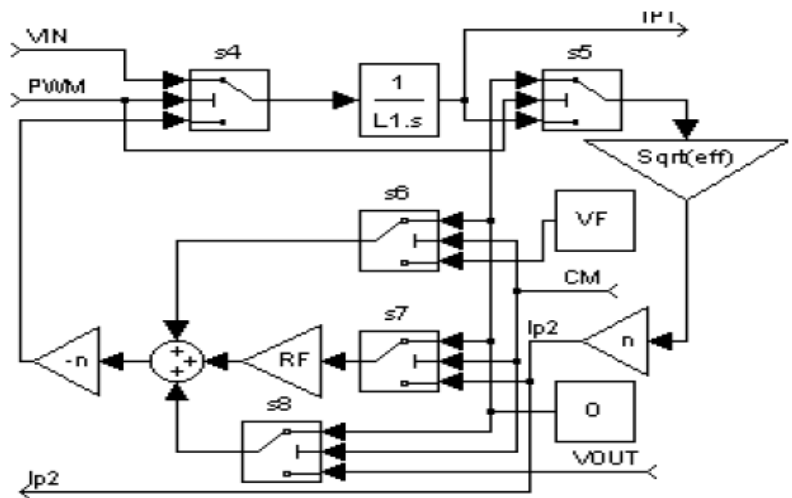

(d)

Figure 7. Electric circuit realization of simulation models of ACBs: (a) VCC charger, (b) RC filter, (c) RC OUT, and (d) transformer

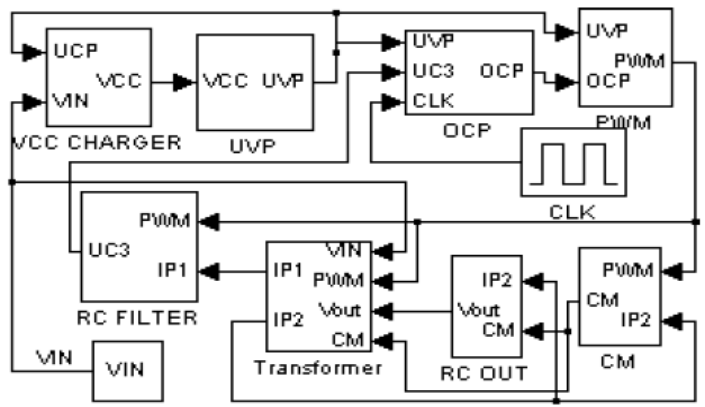

Figure 8. Complete simulation model of the flyback DC-DC converter

\section{SimUlation OF AN EXISTING CONVERTER}

The simulation model is applied to analyze an existing flyback DC-DC converter, which has good performance in the rated load, but was once damaged in the experiment due to a short circuit output at an input voltage of $370 \mathrm{~V}$ DC. The major data of the converter include: input voltage: 102-370 VDC; nominal output voltage: 5 VDC; rated output current: 3.6 A; and switching frequency: $60 \mathrm{kHz}$.

The transformer has a primary winding inductance of $1.186 \mathrm{mH}$, and the numbers of turns of three windings are 96:8:17. Other parameters include: $\mathrm{R} 1=160 \mathrm{~K} \Omega / 1 \mathrm{~W}, \mathrm{C} 1=47$ $\mu \mathrm{F} / 35 \mathrm{~V}, \mathrm{R}_{\mathrm{S}}=1.3 \Omega, \mathrm{R} 4=1.2 \mathrm{~K} \Omega, \mathrm{C} 3=1.0 \mathrm{nF}$, MOSFET: SSS6N60A, R3=0 $\Omega$, D1: MUR1620, D2: UF4006, D3: $1 \mathrm{~N} 4148, \mathrm{R} 2=100 \mathrm{~K} \Omega / 1 \mathrm{~W}, \mathrm{C} 2=3.3 \mathrm{nF} / 1000 \mathrm{~V}$, and $\mathrm{Co}=1000$ $\mu \mathrm{F} / 25 \mathrm{~V}$.

Fig. 9(a) illustrates the simulated operation process of the converter with the rated load while $V_{I N}=102 \mathrm{VDC}$, and $\mathrm{V}_{\mathrm{F}}$ and $R_{F}$ are chosen as $0.7 \mathrm{~V}$ and $0.05 \Omega$. Fig. 9(b) shows the enlarged steady state. It can be seen that Ip1 has an obvious overshoot at starting, which may cause the transformer into the state of saturation and may damage the converter. 




(a) Complete process

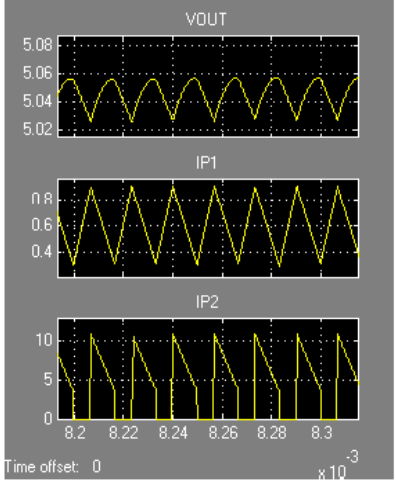

(b) Steady state
Figure 9. Simulated results at the rated load (existing converter)

According to the transformer PC40 $(\mathrm{Bs}=500 \mathrm{mT}$; $\mathrm{t}=100$ ${ }^{\circ} \mathrm{C}$ ) and this converter's characteristic, the rated operating point is $290 \mathrm{mT}$ at Ip1=0.9 A. The margin to the maximum Bs is $210 \mathrm{mT}$, which corresponds to $0.65 \mathrm{~A}$ of Ip1, and hence the maximum Ip1 allowed is $1.55 \mathrm{~A}$. In the rated condition, the maximum current during start-up is $1.2 \mathrm{~A}$, which is less than $1.55 \mathrm{~A}$, so that the converter can work safely. This is consistent to this actual condition.

Under heavy load, e.g. $\mathrm{V}_{\text {IN }}=370 \mathrm{VDC}, \mathrm{Ro}=0.001 \Omega$, the operating process of the converter is analyzed by the proposed model, as shown in Fig. 10, where $V_{F}=0.7 \mathrm{~V}$, $\mathrm{R}_{\mathrm{F}}=0.05 \Omega, \mathrm{R} 1=1600 \Omega, \mathrm{R}_{\mathrm{ICON}}=30 \Omega$. From the simulation results, one can get $\mathrm{V}_{\text {OUT }} \approx 0 \mathrm{~V}$, Ip1 $\max =2.16 \mathrm{~A}$, Ip1min $=1.96$ A, Ip2max=25.92 A and Ip2min=23.52 A. The primary current Ip1 goes over the allowed value, and the converter could be damaged instantly. This is consistent to the actual case that the converter was once damaged in the experiment of short circuit output.

The converter is re-designed by modifying the circuit and parameters. Fig. 11 illustrates the simulated results of the new converter under heavy load $\left(\mathrm{V}_{\mathrm{IN}}=370\right.$ VDC, $\mathrm{Ro}=0.00$ $1 \Omega$ ). New parameters include: $\mathrm{R}_{\mathrm{S}}=1.15 \Omega, \mathrm{R} 4=100 \Omega$, $\mathrm{C} 3=470 \mathrm{pF}$. The new simulation results are Ip1max $=0.98 \mathrm{~A}$, Ip1min=0.8 A, Ip2max=11.76 A, Ip2min=9.6 A. As Ip1max is less than the allowed value, it will not cause the transformer into the saturation state.

Fig. 12 plots the simulation results of the new converter at the rated condition $\left(\mathrm{V}_{\mathrm{IN}}=102 \mathrm{VDC}, \mathrm{Ro}=1.39 \Omega\right)$, which is similar to that of the old converter (Fig. 9). The only difference between them is that there is no overshoot in Fig. 12, implying that the new converter also has higher safety than the existing one during the process of start up.

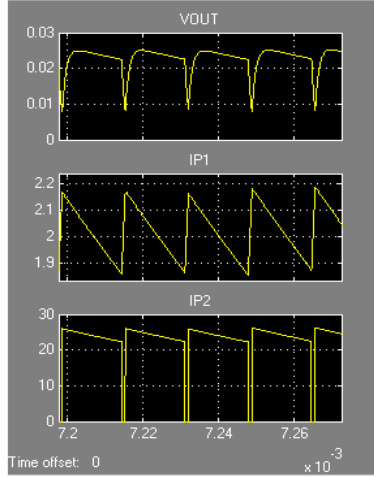

Figure 10. Process under short circuit output (existing converter)

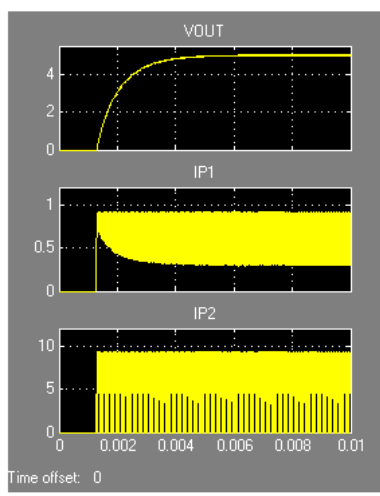

(a) Complete process



Figure 11. Process under short circuit output (new converter)



(b) Steady state
Figure 12. Simulated results at the rated load (new converter)

\section{CONCLUSION}

This paper has systematically presented a procedure to simulate flyback switching DC-DC converters under heavy loads based on the theory of energy self holding and the atomic circuit blocks. An existing converter is analyzed by the presented simulation model and is found to be likely damaged under a heavy load. The converter is redesigned and its reliability is significantly improved.

\section{REFERENCES}

[1] Z.S. Zhang, Theory and Design of Switching Converters (in Chinese), Beijing: Electronics Industry Publishing Company, 1999.

[2] C.W. Liaw, S.J. Chiang, C.Y. Lai, K.H. Pan, G.C. Leu, and G.S. Hsu, "Modeling and controller design of a current-mode controller converter," IEEE Trans. Industrial Eletronics, Vol.41, pp.231-240, 1994.

[3] T.H. Chen, W.L. Lin, and C.M. Liaw, "Dynamic modeling and controller design of fly back converter," IEEE Trans. Aerospace and Electronics Systems, Vol.35, pp.1230-1234, 1999.

[4] J.X. Chen, "Energy self-holding in flyback switching DC-DC converters," in Proc. Int. Conf. Electrical Machines and Systems, Nanjing, China, pp.1194-1197, Sept. 27-29, 2005. 